\title{
INCUBADORAS TECNOLÓGICAS E UNIVERSIDADE: CONTRIBUIÇÃO PARA O DESENVOLVIMENTO DE NOVAS TECNOLOGIAS E EMPREENDEDORISMO: ESTUDO DE CASO NA INTEPP
}

Luis Horácio Isique, Cintia Lopes Evangelista, Emerson Silas Dória, Moacir Del Trejo, Haroldo Cesar Alessi.

Universidade do Oeste Paulista - UNOESTE, INTEPP Incubadora Tecnológica de Presidente Prudente, Presidente Prudente, SP. E-mail: luis.isique@intepp.com.br

\section{RESUMO}

As incubadoras de empresas de base tecnológica são ambientes favoráveis para o desenvolvimento inicial de negócios que agreguem inovação e tecnologia que convergem nos três relevantes fenômenos da economia contemporânea: empreendedorismo, inovação e relações universidade-empresa. O presente trabalho possui o objetivo de analisar a influência e contribuição da Incubadora Tecnológica de Presidente Prudente para o desenvolvimento de novas tecnologias, empresas e empreendedorismo. A metodologia utilizada na pesquisa foi estudo de caso de natureza qualitativa. Foram pesquisados e levantados dados através de pesquisa documental e entrevista com a administração da incubadora. Os resultados demonstram que a incubadora recebe forte apoio de seus parceiros, tornando-se assim um importante movimento para o crescimento econômico regional, aumentando o número de empresas de base tecnológica e consequentemente gerando emprego e renda, além de oferecer a baixo custo infraestrutura que permite aos empreendedores iniciarem o desenvolvimento de seus empreendimentos e trocarem experiências.

Palavras-chave: Incubadora tecnológica; universidade; desenvolvimento regional; emprego; renda.

\section{TECHNOLOGICAL INCUBATORS AND UNIVERSITY: CONTRIBUTION TO THE DEVELOPMENT OF NEW TECHNOLOGIES AND ENTREPRENEURSHIP: A CASE STUDY IN INTEPP}

\begin{abstract}
Incubators of technology-based companies are favorable environments for the initial development of businesses that add innovation and technology converge in the three relevant phenomena of contemporary economy: entrepreneurship, innovation and university-industry relations. This work has the objective of analyzing the influence and contribution of Presidente Prudente Technology Incubator to develop new technologies, business and entrepreneurship. The methodology used in the research was a case study of a qualitative nature. Data were researched and collected through desk research and interviews with the management of the incubator. The results show that the incubator receives strong support from its partners, thus making it is an important move for regional economic growth by increasing the number of technology-based companies and consequently generating jobs and income, as well as offering low-cost infrastructure that allows entrepreneurs begin developing their projects and exchange experiences.
\end{abstract}

Keywords: Technology incubator; university; regional development; employment; income. 


\section{INTRODUÇÃO}

Atualmente o empreendedorismo se tornou tema em grandes discussões, no que tange o desenvolvimento regional, tecnológico e estímulo à inovação em universidades com o apoio de incubadoras tecnológicas. No Brasil são comuns os estudos afirmando a importância das incubadoras na promoção de desenvolvimento, considerando a atuação dos laboratórios acadêmicos. (BAÊTA; BORGES; TREMBLAY, 2006).

As incubadoras de empresas passaram a constituir um ambiente favorável de ideias e oportunidades especialmente para as micro e pequenas empresas. Neste contexto, a incubação de negócios é um processo que suporta e acelera o desenvolvimento de novos empreendimentos, ao prove-los com disponibilidade de recursos e serviços. O principal objetivo de uma incubadora tecnológica é produzir empresas que ao concluírem o programa estarão economicamente viáveis e capazes de exercer suas funções com estabilidade. Estes novos empreendimentos terão o potencial de criar novos empregos, comercializar novas tecnologias, e fortalecer a economia local e nacional. (CAPELARI; ABBADE, 2011).

Diante do exposto, o presente trabalho tem por objetivo apresentar o apoio oferecido pela incubadora às micro e pequenas empresas de base tecnológica e sua influência no desenvolvimento de novas tecnologias e empreendedorismo na região de Presidente Prudente.

\section{METODOLOGIA}

No que tange aos procedimentos metodológicos, foi utilizada de múltiplas metodologias. Inicialmente foi realizada revisão da literatura em livros e artigos acerca do tema. Segundo Marconi (2010, p. 57) "a bibliografia oferece meios para definir, resolver, não somente problemas já conhecidos, como também explorar novas áreas, onde os problemas não se cristalizaram suficientemente". Após o levantamento bibliográfico foi utilizado o método de estudo de caso, houve a coleta de informações extraídas proveniente de relatórios administrativos e por um representante da administração da INTEPP. Segundo Yin "como método de pesquisa, o estudo de caso é usado em muitas situações, para contribuir ao nosso conhecimento dos fenômenos individuais, grupais, organizacionais, sociais, políticos e relacionados." (p. 4, 2015). 
A INCUBADORA E O DESENVOLVIMENTO TECNOLÓGICO E REGIONAL

Os laboratórios tecnológicos tem o propósito de estimular o empreendedorismo, fortalecimento e desenvolvimento de empresas com base em tecnologia. (BAÊTA; BORGES; TREMBLAY, 2006).

Segundo Chiavenato (2012) empreendedor é o termo utilizado para qualificar o indivíduo que detém conhecimento de forma especial, inovadora ao dedicar-se às atividades econômicas na geração de emprego e renda, transformador de conhecimentos em serviços e produtos. $O$ empreendedorismo contribui de forma positiva para o desenvolvimento da economia, ao evidenciar sua capacidade de geração de emprego e renda.

Atualmente a revolução nas tecnologias da informação têm criado enormes oportunidades para as empresas baseadas no conhecimento, bem como desafios para os planejadores ao criar novos postos de trabalho. (LALKAKA, 2003). Para que haja sustentabilidade no empreendimento é necessário estabelecer conexão entre ideias inovadoras, educação empreendedora e o apoio oferecido pelas incubadoras tecnológicas para que os novos empreendimentos sejam capazes de solidificar-se no mercado.

A criação e o desenvolvimento de pequenas empresas tornam-se fundamentais para a sustentabilidade do país, contribuindo para a geração de empregos, o desenvolvimento e crescimento econômico. (LOPES JR, SOUZA, 2005).

O desenvolvimento econômico é resultado do grau de empreendedorismo de uma comunidade, cujas características de liderança, capacidade e perfil coordenem o processo de desenvolvimento, cujas raízes estão, sobretudo em valores culturais, na forma de ver o mundo (LEMES JR; PISA, 2010). Neste sentido a solidificação de novas empresas aliada a força em pesquisa da universidade e as ideias inovadoras da comunidade apresentam consequências positivas no desenvolvimento econômico.

\section{RESULTADOS}

\section{Incubadora Tecnológica de Presidente Prudente - INTEPP}

Em 2001 através do Edital do Serviço Brasileiro de Apoio às Micro e Pequenas Empresas (SEBRAE), iniciou o desenvolvimento do projeto INTEPP para a implantação da Incubadora Tecnológica de Presidente Prudente. Os associados fundadores Unoeste Informática Junior (UNINFO JR) - Empresa Júnior de Informática da Universidade do Oeste Paulista (UNOESTE), com apoio da Faculdade de Informática de Presidente Prudente (FIPP), Associação Comercial e Empresarial de Presidente Prudente (ACIPP), Faculdade de Ciência e Tecnologia da Universidade 
Estadual Paulista (FCT-UNESP) e Prefeitura Municipal de Presidente Prudente reuniram-se para desenvolver o projeto que fora contemplado pelo edital em questão.

A INTEPP (Incubadora Tecnológica de Presidente Prudente) é uma incubadora de base tecnológica e iniciou suas atividades em 29 de Março de 2004. A infraestrutura e serviços oferecidos aos empreendedores desde a fundação da INTEPP em 2004 passou a ser considerada pequena pela diretoria executiva da INTEPP em meados de 2010. Em busca de melhorias para a incubadora e através do convênio firmado com a Secretaria de Desenvolvimento Econômico, Ciência e Tecnologia do Governo do Estado de São Paulo e a INTEPP no ano de 2013, passou a integrar a Rede Paulista de Incubadoras de Base Tecnológica (RPITEC), a partir deste convênio foi possível submeter um projeto para a obtenção de recursos financeiros para a Melhoria da Infraestrutura da INTEPP. Em contrapartida financeira e econômica a UNOESTE disponibilizou e reformou um amplo ambiente para acomodar os novos equipamentos e móveis.

\section{Infraestrutura oferecida pela incubadora}

Atualmente, a INTEPP possui novas e modernas instalações, um prédio com quinhentos e um metros quadrados com infraestrutura composto por: rede elétrica, água, rede de computadores, telefonia, banheiros masculino e feminino, serviços de segurança e limpeza.

A incubadora oferece toda a sua infraestrutura básica aos empreendedores. O prédio está divido em dezoito salas com capacidade para até vinte e quatro empresas separadas nas modalidades de pré-residência e residência, um Laboratório de Experimentação e Inovação (LEI) com equipamentos (tabletes Apple ${ }^{\circledR}$ e Samsung ${ }^{\circledR}$ ) para testes de softwares e aplicativos para os dois sistemas operacionais, uma sala de convivência, cozinha completa, secretaria, sala de gerência e reuniões, todas as salas possuem ar-condicionado, armários, mesas e computadores de última geração.

\section{Processo de seleção de projetos}

O processo de seleção dá-se através de um edital público e disponibilizado no endereço eletrônico (site) da incubadora. O(s) candidato(s) apresenta seu projeto a uma banca avaliadora, constituída por membros da coordenadoria técnica e por profissionais de mercado. De acordo com o edital o projeto deve ser apresentado através de um plano de negócios (Modelo CANVAS), um Sumário Executivo e em forma de apresentação multimídia. É necessário que obtenha uma nota igual ou superior a sete através da somatória dos itens Avaliação Mercadológica, Avaliação 
do Perfil Empreendedor, Avaliação Técnica/Qualidade e Consideração Final sobre os Negócios, e seus respectivos Critérios e Pesos, conforme seguem as tabelas 1,2, 3 e 4 .

Tabela 1. Avaliação Mercadológica

\begin{tabular}{|l|}
\hline \multicolumn{1}{|c|}{ Avaliação Mercadológica - " Peso 4" } \\
\hline \multicolumn{1}{|c|}{ Critérios } \\
\hline Conhecimento do diferencial para o mercado \\
\hline Conhecimento dos concorrentes \\
\hline Conhecimento do público-alvo e perfil do consumidor \\
\hline Resumo Executivo (apresenta claramente o negócio objetivado) \\
\hline Definição da atividade \\
\hline Definição do segmento \\
\hline Diferencial comparado aos concorrentes \\
\hline Estratégia de divulgação e marketing (objetivos qualitativos e quantitativos) \\
\hline Capacidade financeira (conhecimento do investimento inicial necessário) \\
\hline Conhecimento do mercado (panorama e tendências) \\
\hline Maturidade do empreendimento a que se propõe. \\
\hline
\end{tabular}

Tabela 2. Avaliação do Perfil Empreendedor

\begin{tabular}{|l|}
\hline \multicolumn{1}{|c|}{ Avaliação do Perfil Empreendedor - " Peso 3" } \\
\hline \multicolumn{1}{|c|}{ Critérios } \\
\hline Dimensionamento do pessoal que compõem a empresa (no de participantes) \\
\hline Experiência Empresarial \\
\hline Demonstração de competência gerencial \\
\hline Visão de futuro \\
\hline Sinergia entre os participantes da empresa \\
\hline
\end{tabular}

Tabela 3. Avaliação Técnica/Qualidade

\begin{tabular}{|l|}
\hline \multicolumn{1}{|c|}{ Avaliação Técnica/Qualidade - " Peso 2" } \\
\hline Critérios \\
\hline Domínio da tecnologia a ser utilizada pela empresa \\
\hline Demonstração de inovação na tecnologia a ser utilizada pela empresa \\
\hline Utilização de metodologia de gerenciamento de projetos e de qualidade \\
\hline
\end{tabular}

Tabela 4. Consideração Final sobre o Negócio

\begin{tabular}{|l|}
\hline \multicolumn{1}{|c|}{ Consideração Final sobre os Negócios - Peso 1} \\
\hline \multicolumn{1}{|c|}{ Critérios } \\
\hline $\begin{array}{l}\text { Já apresenta todas as características de uma empresa Está } \\
\text { maduro o suficiente para se tornar empresa }\end{array}$ \\
\hline Avaliado positivamente, porém com ressalvas * \\
\hline Muitas falhas apresentadas \\
\hline Total falta de amadurecimento do negócio \\
\hline
\end{tabular}


Os itens de cada critério recebem notas de zero a dez, após a somatória é aplicado o peso da cada item conforme as tabelas 1, 2,3 e 4 .

\section{Empresas Incubadas na INTEPP}

Desde a sua fundação, a incubadora vem contribuindo para o desenvolvimento de novos negócios, tecnologia e fomentando o empreendedorismo. As empresas incubadas na INTEPP desde o inicio de suas atividades em 29 de Março de 2004 até Agosto de 2015, totalizam vinte e sete empresas, conforme a tabela a seguir.

Tabela 5. Quantidade de Empresas

\begin{tabular}{|c|c|}
\hline Ano & Quantidade de Empresas \\
\hline 2008 & 9 \\
\hline 2009 & 3 \\
\hline 2010 & 2 \\
\hline 2011 & 1 \\
\hline 2012 & 1 \\
\hline 2013 & 3 \\
\hline 2014 & 6 \\
\hline 2015 & 2 \\
\hline Total & 27 \\
\hline
\end{tabular}

A tabela 5 demonstra o total de empresas que entraram, entretanto, é percebido que nos anos inicias foram totalizados a partir do ano de 2008 devido ao melhoramento dos processos de ingresso e egresso das empresas.

\section{Graduação}

A INTEPP em onze anos graduou oito empresas de base tecnológica, as empresas graduadas pertencem aos segmentos comerciais de desenvolvimento de softwares e soluções tecnológicas para web, sistema de controle rural, financeiro, jurídico, gestão empresarial para tomada de decisões e soluções para mapeamento digital de rodovias e ruas, após a graduação alguns projetos foram descontinuados por fatores que levaram aos empreendedores a seguirem novos desafios. Entretanto, três empresas estão consolidadas no mercado de desenvolvimento de softwares (soluções tecnológicas) na cidade de Presidente Prudente e uma foi adquirida por outra empresa do mesmo segmento. 
Os nomes das empresas foram substituídos por X, Y e Z para preservar suas identidades e por questões contratuais a incubadora não possui autorização para a publicação de números financeiros e demais informações isoladas das empresas, apenas de forma agregada.

Tabela 6. Quantidade funcionários direto

\begin{tabular}{|c|c|}
\hline Quantidade & Empresa \\
\hline 8 & $\mathrm{X}$ \\
\hline 2 & $\mathrm{Y}$ \\
\hline 2 & $\mathrm{Z}$ \\
\hline
\end{tabular}

Não foi possível identificar o faturamento das empresas devido às informações serem sigilosas. Entretanto, estima-se que os salários dos funcionários sejam de aproximadamente R\$ 3.413,00 (Três mil, Quatrocentos e Treze Reais), devido suas funções e atribuições de programadores (média realizada através de dados publicados pela revista Info). Para o calculo salarial foi levado em consideração, oito cargos de programadores juniores e seus respectivos valores salarias da categoria.

\section{DISCUSSÃO}

Atualmente o empreendedorismo está em evidência como estratégia para geração de emprego e renda, entretanto a falta de cultura empreendedora, infraestrutura básica e cursos de capacitações, são colocados como obstáculos para o desenvolvimento local e regional.

Em decorrência da necessidade de estímulo ao empreendedorismo as incubadoras de empresas tecnológicas tem a finalidade de contribuir para o desenvolvimento econômico, pois oferecem suporte desde a concepção até análise de viabilidade financeira de ideias inovadoras.

\section{CONCLUSÃO}

Com base nos dados levantados identificou-se que a incubadora possui uma infraestrutura composta por salas de uso compartilhado para a modalidade de pré-residência e salas individuais para a modalidade de residência, cujas instalações atendem perfeitamente a necessidade dos empreendimentos nas respectivas fases.

Por fim, conclui-se que $29,62 \%$ das empresas que entraram na incubadora conseguiram graduar-se, sendo que quatro empresas e seus projetos foram descontinuados, uma empresa fora adquirida por outra, e três empresas encontra-se consolidadas com seus projetos aperfeiçoados e geram doze empregos diretos, apenas para as funções de programadores para desenvolvimento 
de softwares. Através dos dados apresentados é possível observar a influência da INTEPP no desenvolvimento de novas tecnologias e empreendedorismo na região de Presidente Prudente.

\section{REFERÊNCIAS}

BAÊTA, Adelaide Maria Coelho; BORGES, Candido Vieira; TREMBLAY, Diane-Gabrielle. Empreendedorismo nas incubadoras: Reflexões sobre tendências atuais. Comportamento organizacional e gestão, v. 12, n. 1, p. 7-18, 2006.

CAPELARI, NICOLE; ABBADE, EDUARDO BOTTI. Incubadoras Tecnológicas e o Apoio Ao Empreendedorismo. VIII Simposio de Excelência em Gestão e Tecnologia, 2011.

CHIAVENATO, Idalberto. Empreendedorismo: dando asas ao espírito empreendedor. -4.ed.Barueri, SP: Manole, 2012.

LALKAKA, Rustam. Business incubators in developing countries: characteristics and performance. International Journal of Entrepreneurship and Innovation Management, v. 3, n. 1-2, p. 31-55, 2003.

LEMES JR, Antonio Barbosa. PISA, Beatriz Jackiu. Administrando Micro e Pequenas Empresas - 2a ed. Rio de Janeiro: Elsevier, 2010.

LOPES JR, Gumersindo Sueiro; DE SOUZA, Eda Castro Lucas. Atitude empreendedora em proprietários-gerentes de pequenas empresas. Construção de um instrumento de medida. Revista Eletrônica de Administração, v. 11, n. 6, 2005.

MARCONI, Mariana de Andrade, LAKATOS, Eva Maria. Técnicas de pesquisa: planejamento e execução de pesquisas, amostragens e técnicas de pesquisa, elaboração, análise e interpretação de dados. -7 ed. - 3. Reimpr. - São Paulo: Atlas, 2010.

REVISTA INFO. Tabela de salários digitais. 2012. Disponível em: <http://info.abril.com.br/carreira/salarios> Acesso em: 19 agosto 2015.

YIN, Robert K. Estudo de Caso. Planejamento e Métodos. 5a ed. São Paulo: Bookman, 2015. 